\title{
Representações de Patrimônio Arquitetônico: para documentar, difundir e tocar
}

\author{
Representations of Architectural Heritage: for documenting. disseminating and touching
}

\author{
> Ana Paula Dametto \\ Universidade Federal de Pelotas, Brasil \\ anapauladametto@hotmail.com \\ > Monica Veiga \\ Universidade Federal de Pelotas, Brasil \\ monika_veiga@hotmail.com
}

\author{
$>$ Janice de Freitas Pires \\ Universidade Federal de Pelotas, Brasil \\ janicefpires@hotmail.com \\ > Adriane Borda Almeida da Silva \\ Universidade Federal de Pelotas, Brasil \\ adribord@hotmail.com
}

\begin{abstract}
In this paper experiences of documenting an artifact of cultural interest are reported, these experiences were made possible by the interaction between researchers of two areas of study: Memory and Heritage and Digital Graphic Representation. These experiences include building a registration form, obtaining models in virtual reality, augmented reality and 3D printing. The different perceptual dimensions that each type of description can add to an inventorial system were observed as well as which organizational and access to information implications each of these types requires from such a system.
\end{abstract}

Keywords: architectural heritage; architectural documentation; advanced technologies of representation and visualization; metallic artifacts.

\section{Introdução}

A documentação do patrimônio arquitetônico é tema de relevância social para a preservação da memória, a qual, segundo Halbwachs (1976), é reconstruída a cada tempo, de acordo com o "quadro social" que se estabelece. A constituição de acervos documentais sobre o patrimônio cultural tem sido impulsionada, no Brasil, por órgãos como IPHAN (Instituto do Patrimônio Histórico e Artístico Nacional) que através de instrumentos como SICG (Sistema Integrado de Conhecimento e Gestão) e de programas como PNPI (Programa Nacional de Patrimônio Imaterial) desenvolve Inventários de Conhecimento e políticas de preservação direcionadas à salvaguarda de bens culturais de natureza material e imaterial.

Os inventários constituem sistemas organizacionais voltados à preservação da memória social e ao conhecimento do patrimônio cultural. Tradicionalmente, se utilizam de fichas para registro de dados que variam em forma e conteúdo a depender do objetivo do inventário e do tipo de bem cultural. Com apoio das Tecnologias de Informação e Comunicação, TICs, nos últimos anos, tem existido um esforço para que tais fichas sejam transpostas para sistemas de banco de dados, gerando assim uma infraestrutura para facilitar o acesso a esta informação. Entretanto, ainda poucas são as iniciativas que ultrapassam o propósito de gerar um banco de dados e que usufruem das potencialidades atuais das TICs para fins inventariais em seu sentido mais amplo.

A virtualização da informação (LÉVY, 1999) de um bem cultural aumenta as possibilidades de representaçóes deste mesmo bem e potencializa a informação para a construção da memória social.
Técnicas de realidade virtual, realidade aumentada, impressão 3D, por exemplo, permitem promover experiências representacionais capazes de atribuir diferentes dimensóes perceptivas à documentação patrimonial. Dimensôes que dificilmente seriam percebidas a partir de linguagens textuais ou até mesmo gráficas, como podem ser àquelas obtidas a partir de experiências táteis. Neste trabalho relatam-se experiências de documentação de um artefato de interesse cultural, oportunizadas pela interação entre pesquisadores de duas áreas de estudo: Memória e Patrimônio e Representação Gráfica Digital. Estas experiências incluem a construção de uma ficha cadastral, a obtenção de modelos em realidade virtual, realidade aumentada e impressão 3D. Parte-se do propósito de observar as diferentes dimensôes perceptivas que cada tipo de descrição pode adicionar a um sistema inventarial e quais implicaçôes organizacionais e de acesso à informação são geradas quando adicionadas a tal sistema.

\section{Metodologia}

A etapa de revisão bibliográfica compreende o estudo de conceitos que envolvem as áreas de Memória e Patrimônio sobre documentação arquitetônica digital, e o reconhecimento de inventários para o patrimônio cultural. Incluiu estudos na área de Representação Gráfica Digital, particularizando as tecnologias avançadas de representação e visualização. Abrange também estudos na área de ciência da informação e ainda de acessibilidade sobre a caracterização de modelos táteis para a percepção da forma por pessoas com deficiências visuais. A etapa de desenvolvimento compreendeu a seleçáo de um determinado artefato de interesse patrimonial, e a realização 
de experiências de documentaçáo. Neste momento executam-se as análises das experiências, buscando-se identificar parâmetros que possam ser associados a cada tipo de documentação desenvolvida. Para a delimitação dos parâmetros, especialmente em relação aos modelos táteis ainda serão feitos ensaios com o uso dos modelos gerados por pessoas com deficiência visual. Logo, os resultados destas análises serão discutidos e confrontados observando-se o grau de complementaridade ou de sobreposiçáo da informaçáo advindo de cada tipo de documentação. Para a etapa final está previsto o registro sistematizado das reflexôes visando a constituição de diretrizes para novas experimentaçôes e de métodos de documentação do patrimônio arquitetônico que se utilizem das potencialidades atuais das TICs.

\section{Resultados}

Em um contexto de investigação na área de Memória Social e Patrimônio Cultural, o balcão metálico foi descrito e analisado através de um inventário "Os Metais nas Fachadas Públicas Pelotas, RS. (1870-1931)”, o qual contempla uma ficha cadastral e registros fotográficos do artefato. A metodologia empregada para o cadastramento permitiu identificar dezesseis tipologias de componentes arquiteturais metálicos. Também possibilitou verificar as relaçóes entre as edificaçóes de interesse cultural e as tipologias de artefatos metálicos integrados, como por exemplo: a frequência de determinada tipologia relacionada ao período histórico e ao uso da edificação; a localização dos artefatos no espaço compositivo das fachadas; procedência dos componentes metálicos. Além destas relaçóes foram identificadas as principais técnicas, características construtivas e tipos de metais empregados no período analisado; as tendências estilísticas expressas nos artefatos pela análise formal e a elaboração de um glossário de elementos compositivos que se repetiam nestes componentes arquiteturais integrados. Cabe destacar que os inventários, entendidos como práticas voltadas ao cadastro e conhecimento de bens de interesse cultural realizados por instituiçóes de preservação e salvaguarda do patrimônio cultural e no meio acadêmico, nem sempre possuem um formato acessível ao público em geral. O método de ordenação das informaçóes na ficha cadastral (ou grade interpretativa) deste inventário apresentou uma interface visualmente acessível ao meio acadêmico, embora o objetivo primeiro do inventário tenha sido unicamente gerar a possibilidade de analisar, sob diferentes aspectos, a manifestação dos artefatos das fachadas públicas da cidade de Pelotas, RS, entre 1870 e 1931 - tema este desenvolvido em dissertação de mestrado.

Após cumprir o primeiro objetivo, estritamente acadêmico, iniciou-se um estudo para a reordenação destes dados, utilizando uma base mais acessível e interativa, com acréscimo de diferentes representaçôes, como a modelagem virtual e a realidade aumentada, tendo como pano de fundo a pesquisa sobre a manifestação dos metais na arquitetura e na cidade de Pelotas. Com o objetivo de enriquecer a experiência de pesquisa ou a simples curiosidade para apropriação de um conhecimento importante à educaçáo patrimonial e que portanto deveria atingir um público maior, além da fronteira acadêmica, iniciou-se este processo que neste primeiro momento aborda as características e aplicaçóes potenciais de cada experiência de representaçáo citada.
Em um contexto de investigação em representação gráfica digital foram desenvolvidas representaçóes: a) digitais em realidade virtual, disponibilizando-se modelos diferenciados do artefato para a obtenção de imagens estáticas, para animação e para visualização em tempo real através de modelos em diferentes resoluções; b) digitais, para realidade aumentada; c) físicas, a partir de impressão 3D.

$\mathrm{O}$ artefato documentado refere-se a um balcão metálico, pertencente a uma edificação com características ecléticas, que faz parte de um conjunto de imóveis tombados pelo IPHAN em um centro histórico e urbano, localizado no entorno da Praça Coronel Pedro Osório, número 2, e ilustrado na primeira linha da figura 2. A construção foi edificada no estilo colonial no início do séc. XIX e sofreu alteraçôes em 1880, quando sua aparência foi alterada para o estilo eclético. Integra o maior conjunto arquitetônico deste estilo preservado na América Latina e atualmente tombado pelo IBPC (verificar esta informação), abriga a Secretaria Municipal de Cultura da cidade de Pelotas (SECULT) em seu andar superior e um centro cultural em seu andar inferior.

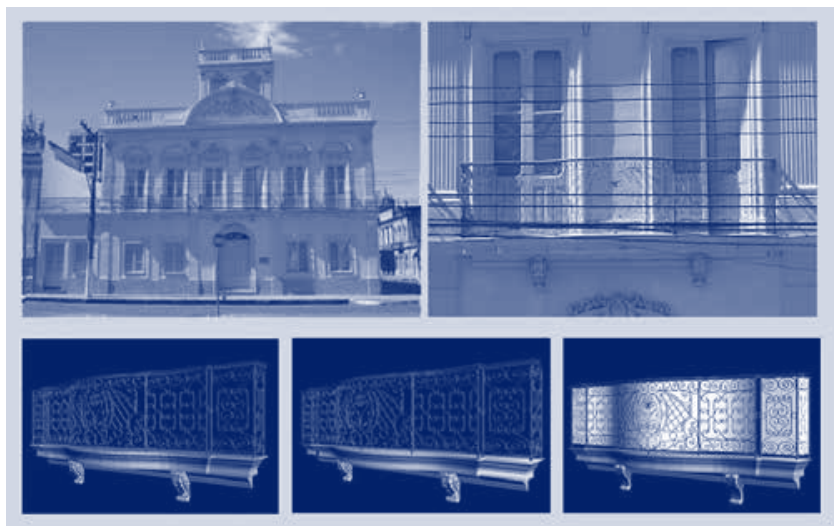

Figura 2: Casarão 02, Praça Coronel Pedro Osório; detalhe da sacada central e três modelos geométricos com diferentes níveis de otimizaçáo geométrica. Fonte: Pires e Borda (2007).

a. Modelos digitais em realidade virtual

Inicialmente este elemento arquitetônico foi adotado como objeto de estudo para atividades de representação gráfica digital desenvolvidas em nível de pós-graduação. Estas atividades naturalmente foram sendo inseridas no Projeto Modela Pelotas (Borda et al, 2005), que tem o objetivo de estruturar processos de representação gráfica digital do patrimônio da cidade de Pelotas. A metodologia adotada contou com as etapas de análise geométrica do artefato e formulação de hipóteses de processos de geração de sua geometria, identificando-se as técnicas adequadas. Foram também investigados processos de otimização geométrica do modelo gerado, para que pudesse ser utilizado em diferentes aplicaçôes, tais como imagens estáticas, animaçốes e visualização em tempo real. Estes experimentos geraram modelos com níveis diferenciados de otimização, os quais estâo ilustrados na segunda linha da figura 2: à esquerda modelo gerado por transformaçóes geométricas complexas aplicadas sobre curvas, resultando em 229 mil polígonos e adequado para visualização por imagens estáticas pela precisão de sua geometria; 
ao centro, modelo gerado a partir de transformaçóes geométricas simples aplicadas em primitivas de modelagem, resultando em 94 mil polígonos, e adequado para visualizaçáo em animaçóes; e à direita desta mesma linha, modelo gerado para interação em tempo real, substituindo-se partes de sua geometria por aplicação de texturas, visando a otimização de seu número de polígonos, neste caso, para 23 mil.

Um dos desdobramentos deste trabalho foi o estudo da resolução de um problema arquitetônico, de visualização dos efeitos de insolaçáa sobre o artefato, produzidos em um ambiente interno, a partir das tecnologias informáticas de representação gráfica. Este permitiu estruturar discursos didáticos que abarcam desde a etapa de modelagem geométrica à parametrização das variáveis que controlam o modelo de simulação de incidência de luz natural sobre o objeto modelado (Pires e Borda, 2007). Cabe destacar que a geometria complexa deste elemento atendeu ao interesse de valorizar o interior do ambiente arquitetônico modelado, considerando o contorno das sombras que a luz natural incidindo sobre ele pode gerar, conforme descrito em Pires e Borda (2007).

A imagem da figura 3 , à esquerda, refere-se a uma vista externa do ambiente modelado para a simulação dos efeitos de iluminação natural, objetivando imagens estáticas, a partir do modelo geométrico com 229 mil polígonos. Para a geração de tal imagem houve a necessidade de identificar uma técnica que simulasse um modelo de iluminação natural e possibilitasse controlar a incidência dos raios luminosos no interior do ambiente, de acordo com a sua localizaçáo geográfica e data e horário específicos. Estes experimentos foram descritos no trabalho referido anteriormente. As condiçóes de iluminação da técnica de luz natural "Sunlight" podem ser observadas ao centro e direita da mesma figura, diferenciando-se a imagem à direita por ter sido aplicado o cálculo de sombras.

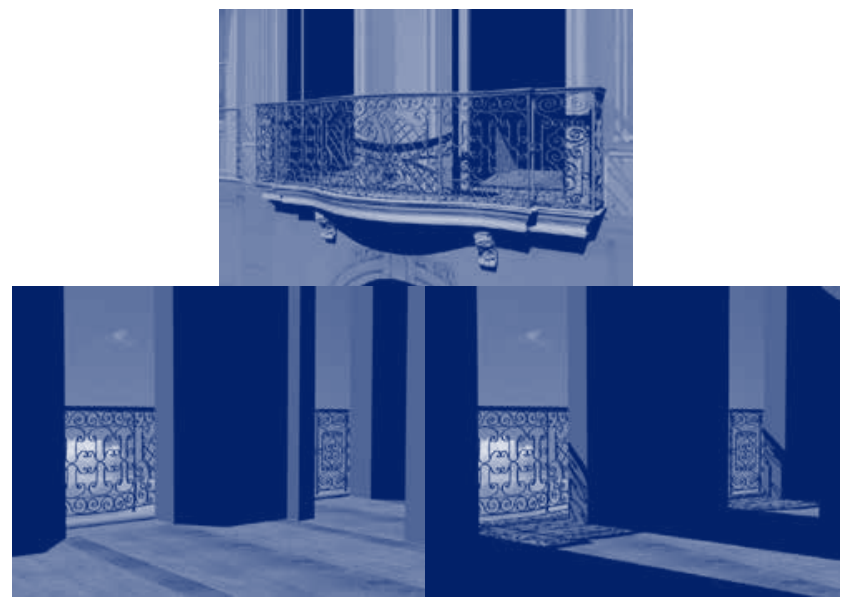

Figura 3: Modelagem do ambiente externo e elemento arquitetônico, simulando luz natural; registro dos efeitos da iluminação sobre o ambiente interno. Fonte: Pires e Borda (2007).

b. Modelos digitais, para realidade aumentada

A técnica avançada de visualização por realidade aumentada envolve movimento, interatividade e processamento de imagens ocorrendo em tempo real, em função das mudanças de ponto de vista do observador, as quais demandam cálculos distintos. Os modelos destinados a tal aplicaçáo devem assim ser gerados com maior otimização geométrica do que aqueles voltados para imagens estáticas e animaçôes. A geração do ambiente e elemento arquitetônicos deve ser realizada a partir da modelagem geométrica de superfícies poliédricas ou planos e a aplicação de texturas da própria geometria do objeto a estas superfícies, as quais a simulam como uma geometria complexa. Segundo Pires e Borda (2007), com tais técnicas há um ganho sob o aspecto de interatividade, porém a fidelidade em relação ao modelo real é altamente reduzida, destacando-se ainda a impossibilidade de aplicaçáo de modelos de iluminação que simulem a geometria das sombras, ou a delimitação das manchas de luz. A figura 5 ilustra o modelo do Casaráo 2 e do elemento metálico em sua fachada gerado com o objetivo de interatividade em tempo real e para ser utilizado em realidade aumentada.

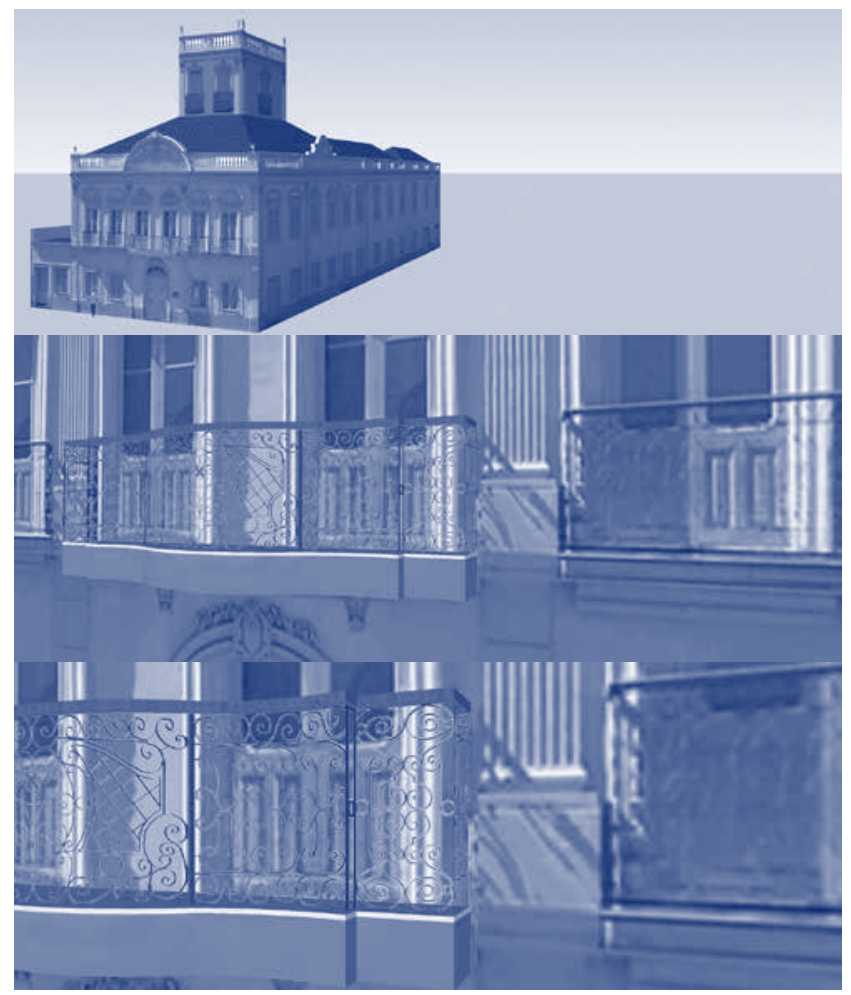

Figura 4: Modelagem do ambiente externo e elemento arquitetônico, para realidade aumentada. Desenvolvida por co-autora.

c. Modelos físicos, a partir de impressão 3D.

Em VEIGA et al, 2013, foram relatados os experimentos do processo de fabricação digital do mesmo balcão metálico que foi alvo de estudo na primeira experiência. Este elemento gerado por técnicas de representação gráfica digital e fazendo parte do acervo de modelos do Projeto Modela Pelotas (BORDA et al, 2012) foi selecionado com o objetivo de avaliar as técnicas digitais de modelagem utilizadas no âmbito de tal projeto e sua adequação as técnicas de fabricação digital. Partindo-se da identificação sobre os principais métodos 
de fabricação digital utilizados na atualidade, os quais empregam técnicas subtrativas, formativas e aditivas para a construção de modelos físicos, buscou-se reconhecer o processo mais adequado à confecção do balcão. Junto a esta foi necessário revisar as técnicas de geração do modelo geométrico até então empregadas, frente as restriçóes técnicas de fabricação digital dos processos identificados. O protótipo do balcáo resultante desta experiência foi exposto em um evento comemorativo ao Turismo, juntamente com outros modelos com o intuito de despertar o interesse da comunidade para valorizaçáo deste patrimônio. Durante a exposiçáo do modelo à comunidade pode-se observar uma "renovação do interesse da populaçáo pelos artefatos metálicos presentes na arquitetura pelotense", pois estes, muitas vezes, passam despercebidos aos olhares rotineiros dos habitantes que transitam pelo centro histórico.

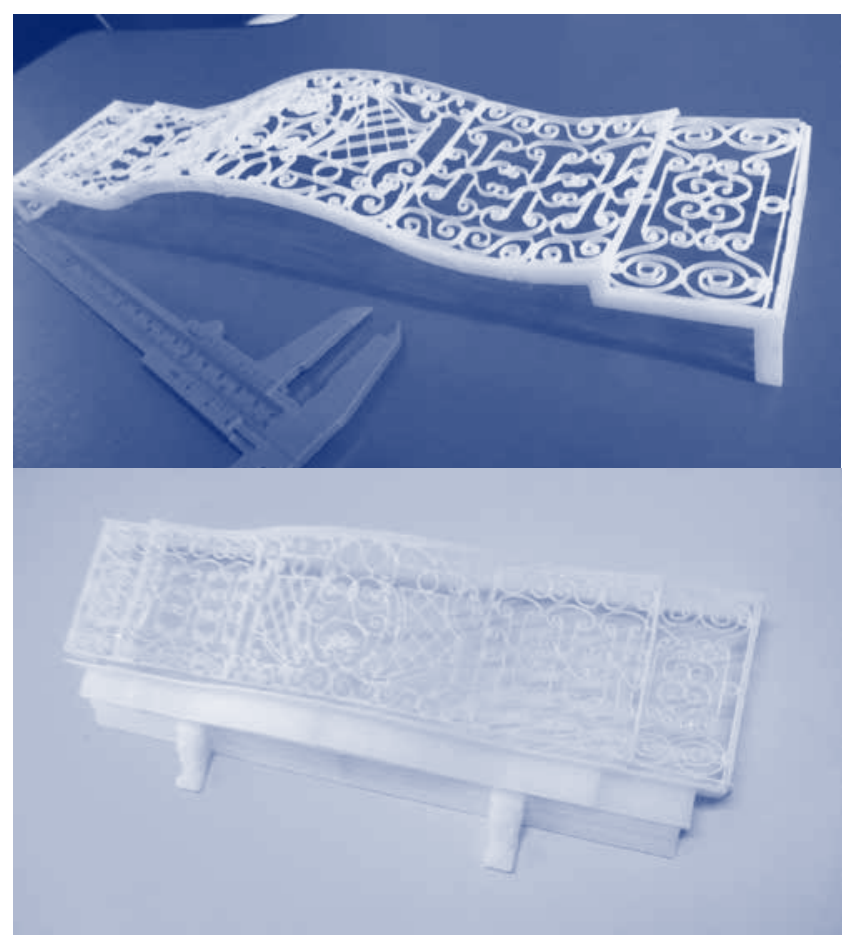

Figura 5. Grade fabricada por impressão $3 D$; maquete da sacada resultante.

\section{Conclusão}

Considera-se que os resultados até então obtidos promoveram a construção de conhecimento sobre o artefato metálico em questâo. As representaçôes tem sido utilizadas em açôes de difusão do patrimônio arquitetônico. $\mathrm{O}$ estudo tem integrado pesquisadores de diferentes áreas, potencializando cada uma delas. Espera-se que as reflexóes que estão sendo realizadas possam se estabelecer como diretrizes para a estruturação de sistemas que avancem na elaboração de açóes que inter-relacionem diferentes formas de representação para a difusão do patrimônio cultural e explorem as tecnologias avançadas de representação e visualização para a reconstrução da memória social a partir de novos estilos de raciocínios e de acessos ao conhecimento e à informação.

\section{References}

Candau, J. Memória e Identidade. Tradução de Maria Letícia Ferreira. São Paulo: Contexto, 2012.

Dametto, A. P. A.; Gutierrez, E. B.; Kindlein Junior, W. O inventário dos componentes arquiteturais metálicos das fachadas públicas de Pelotas, RS, Brasil - (1870 a 1931). In: Congreso Internacional de Materiales, 2011, Bogotá, Colombia. Congreso Internacional de Materiales (6.: 2011 nov. 27-30 : Bogotá, D.C., Colombia). Bogotá : Universidade de Los Andes, 2011. v. 1. p. SE-ED-005-8fl., 2011. v. v. 1. p. 27-30.

Halbwachs, M. Les cadres sociaux de la mémoire. Paris: Mouton, 1976.

IPHAN. Patrimônio Cultural: Patrimônio Material, Patrimônio Imaterial. Disponível em: http://portal.iphan.gov.br/portal/ montarPaginaSecao.do?id=20\&sigla=PatrimonioCultural\&retorno=paginaIphan. Acesso em abril de 2014.

Lévy, P. Cibercultura. Tradução de Carlos Irineu da Costa. São Paulo: Editora 34, 1999.

Lévy, P. O que é o virtual? Tradução de Paulo Neves. São Paulo: Editora 34, 1996.

Pesavento, S. J. História \& História Cultural. Belo Horizonte: Autêntica, 2005.

Pires, J. F.; Silva, A. B. A. Simulação de iluminação natural em ambientes internos por meios digitais: uma abordagem didática. In: GRAPHICA 2007, VII International Conference on Graphics Engineering for Arts and Design e XVII Simpósio Nacional de Geometria Descritiva e Desenho Técnico, 2007, Curitiba. GRAPHICA 2007, VII International Conference on Graphics Engineering for Arts and Design e XVII Simpósio Nacional de Geometria Descritiva e Desenho Técnico. Curitiba: Departamento de Desenho Universidade Federal do Paraná, 2007. p. 1-11.

Primo, A. Interação mediada por computador: comunicação, cibercultura, cognição. Porto Alegre: Sulina, 2011.

Veiga, M.; Xavier, P.; Pires, J. F.; Silva, A. B. A. Impressão 3D de um elemento complexo da arquitetura de Pelotas: relato de uma experiência. XXI Congresso de iniciação cientifica da Universidade Federal de Pelotas, 2013. 